\title{
Changes in the Regional Legal Space in the Context of International Cooperation
}

\author{
Tatyana Yuzhakova \\ Department of history,social studies and \\ pedagogicaltechnologies \\ FSBI of HE «Kuban State University» \\ branch in Slavyansk-on-Kuban, Russia \\ tlyuzhakova@yandex.ru
}

\author{
Alexander Ryabikov \\ Department of history,social studies and \\ pedagogicaltechnologies \\ FSBI of HE «Kuban State University» \\ branch in Slavyansk-on-Kuban, Russia \\ riybicov@mail.ru
}

\author{
Yuri Emelyanov \\ Department of history,social studies and pedagogicaltechnologies \\ FSBI of HE «Kuban State University» \\ branch in Slavyansk-on-Kuban, Russia \\ emelanov@list.ru
}

\begin{abstract}
The development of the modern world community demonstrates changes in the regional structure of the world and the state. Under the influence of political, economic and other factors, there is a variable mobility of interstate and intra-state regional legal spaces. Of particular interest are the processes of transformation of the regional legal space in terms of international cooperation. In this case, there are changes in the qualitative characteristics of the legal systems of the regions, on which depends not only the implementation of the directions of international cooperation of various subjects, but also its prospects.

The aim of the work is to substantiate the regularities and features observed in the course of changes in the regional legal space as a state-legal and socio-cultural phenomenon in the conditions of international cooperation. System and synergetic approaches, dialectical and comparative methods were used in the research process.

The authors consider the properties, functions, priority directions of development of the regional legal space in the conditions of international cooperation. In their opinion, the regional legal space is an open, mobile, self-organizing system with a social meaning and purpose. Regional legal space is the most important legal phenomenon characterized by substantial volume.

The findings of the study can be used for further formation of the image of the regional legal space in the theoretical and legal science.
\end{abstract}

Keywords: regional legal space, international cooperation, integration, synergetic and systemic approaches, legal system, the implementation of the law

\section{INTRODUCTION}

The modern world is facing a new stage of its development, within which integration and disintegration processes acquire a special sound for States and peoples. One of the factors of these processes is international cooperation, which contributes to the active development of regional legal spaces at the interstate and domestic levels. Since international cooperation includes various areas (economic, political, cultural, humanitarian and others), the mobility of regional legal spaces is observed in different aspects. Under the conditions of bifurcation (changes), this process has intensified and demonstrates new characteristics.

\section{METHODS AND RESUltS}

On the basis of the synergetic approach, the category of regional legal space is considered, which makes it possible to identify its place and role in the legal life of society, to see its characteristics in the conditions of international cooperation. G. Haken noted that synergetics can be considered as a theory of "joint action of many subsystems, as a result of which there is a structure and the corresponding functioning" [1, p. 89]. Regional legal space is an element of the legal space of the state or global legal space, which occupies a certain place in the legal organization of the world and is a complex selforganizing system, expressed in the diverse relationships of its structural components [2, p. 39]. The latter are dynamic and characterize the social and territorial diversity and peculiarities of legal life.

The synergetic approach is connected with the system method, which allows us to consider the regional legal space 
as a system that is formed, operating and changing in a mobile environment. It is a set of legal phenomena, legal relations, processes developing within the territorial boundaries of the region and determined by various conditions of social life. One of these conditions is the international cooperation of various actors. In addition, it is the systematic approach that makes it possible to see the features of the development of regional legal spaces in the course of cooperation.

The use of legal comparative studies allows us to compare the features of the formation and development of regional legal spaces and their individual components.

The current reality is that international cooperation is developing at an increasingly rapid pace and is acquiring new regional foundations. This is most evident in the economic sphere. It is enough to name EurAsEC, China's initiative "One belt - One road", to see how ambitious the reality and plans for economic integration of States can be. Its consequences can be not only geo-economic and geopolitical in nature, but have an unconditional importance for the development of the regional legal space.

It should be noted that in the conditions of international cooperation of States, the legal spaces of regions may differ in the level of contact, openness for interaction. In the conditions of international cooperation, the regional legal space is characterized by openness (dissipativity), which is expressed in the design of the appropriate necessary legal framework. For example, in 2014, an agreement was signed on the establishment of the EurAsEC, which, according to the famous Russian scientist A. Y. Kapustin, formalized the "economic and legal space" of this regional international organization. The specified space "can be defined both by the constituent agreement, and other international treaties within the Union, and the territorial scope includes territories of all member States without any exceptions» [3, p. 105]. The openness of the regional legal space contributes to its diversification. Open regional legal spaces are characterized by a willingness to implement communication. In the context of international cooperation, this characteristic is particularly important for achieving positive results by stakeholders. Their discussion of the existing regulations in order to improve and ensure the efficiency of functioning, borrowing the positive experience of other countries or regions emphasizes the property of openness of the regional legal space.

Of interest is the formation of a legal space on the basis of China's initiative "One belt - One road", which is accompanied by various processes. In particular, the created regional legal space covers a large territory and is formed on the basis of openness. This was facilitated by the counterinitiative of the States concerned. For example, Poland in 2012 proposed to implement the "Go China" project aimed at economic cooperation with China, as well as to hold a summit on the "16+1" platform [4, p. 1], which led to the growth of mutually beneficial agreements.

The regional legal space carries out a number of functions that show its internal state. Functions characterize the purpose of the regional legal space. In the context of international cooperation, both universal and special functions are realized. First of all it is communicative, integrative, informative, realization of legal norms, system-forming, axiological, implementation and other functions. The development of regional legal space in the global world contributes to the implementation of international legal norms by including them in the national legal system.

\section{DISCUSSION}

Regional legal spaces are characterized by a degree of order. Disordered spaces are characterized by the presence of a large variability of possible States, instability of the structure. In terms of international cooperation, this situation of the regional legal space is associated with insufficient legal regulation of relations, with the absence of a certain number of necessary regulations. For example, today the regional legal space of the Arctic States has some instability. It would seem that the circle of participants has long been defined, but today the question is raised about its expansion, about the creation of other foundations for collective management of the Arctic region [5, p. 47]. It is surprising that even Poland, located in the center of the European continent, claims to participate in it.

In the context of international cooperation, the complementary nature of regional legal spaces is actively manifested, which is expressed in the desire for interaction on a positive basis. In this case, cooperation is carried out between the States forming the regional legal space, there is a cross-border interaction of territories. Thus, cross-border cooperation on a mutually beneficial basis is planned throughout the economic belt of the silk road, enriching "the States along the route with new opportunities, thanks to infrastructure logistics and trade opportunities" [6, p. 141]. Opposite trends are possible: after economic interaction, antagonism of regional legal spaces can be observed for various reasons. For example, the complexity of relations between Russia and Ukraine has led to the curtailment of cross-border cooperation between the regions of the two countries. As noted by scientists, "In the Bryansk region, agreements have been signed with 22 regions of Ukraine, including trilateral ones, which formally operate, but in fact have ceased to be implemented"[7, p. 53].

Modern international cooperation is a factor contributing to the formation and development of law-mixed (including subjects representing different legal families) regional legal spaces. There is also an active interaction of national legal systems. For example, during the implementation of the project "one belt - one road", close attention is paid to this, within its framework "almost seven dozen States with a population of about 4.5 billion people are already United and have a serious impact on the key processes of our time" [8, p. 164].That is, there is a mutual influence of civilizations, cultures, a large "field of opportunities for the implementation of activities" [9, p. 5] of all subjects included in the regional legal space. This is expressed, inter alia, in the creation of a common conceptual and categorical apparatus of law, "legislation and law enforcement practice" [10, p. 93], aimed at ensuring cooperation. 
space stimulates them to the mutual influence of cultures. The legal aspect plays an important role in this process.

\section{REFERENCES}

[1] G. Haken, Synergetics.Moscow, 1985, p. 424.

[2] T.L. Yuzhakova, Regional legal space: fundamentals of theory and practice: a monograph, 2008, p. 163.

[3] A.Ya. Kapustin, "The Treaty of the Eurasian Economic Union - New Page of Legal Development of Eurasian Integration," Journal of Russian law, vol. 12, 2014, pp. 98-107.

[4] P. Wang, K. Pawlak, "Changes in Foreign Trade in Agricultural Products between China and Poland," Agricultural \& Forestry Economics and Management, vol. 2(1), 2019, pp. 1-10.

[5] D. Vicente, G. Cáceres, "European cooperation: How important country is Poland to ensure the Arctic governance?," Polar Science, vol. 21, 2019, pp. 47-51.

[6] A.M. Akmatalieva, "Perspectives of China's economic belt of silk road in Central Asia," Comparative Politics Russia, vol. 9(4), 2018, pp.139146.

[7] V.A. Kolosov, M.V. Zotova, "Transformation of cross-border interactions on the Russian-Ukrainian borderland after 1914," Comparative Politics Russia, vol. 9(2), 2018, pp. 41-61.

[8] N.A. Sluka, "On the way to paxcinica. In memory of E.N. Samburova," Comparative Politics Russia, vol.10(3), 2019, pp.159-166.

[9] T.Y. Khabrieva, V.Yu. Lukyanova, "Law and economic activity," Social sciences and contemporary world, vol. 3, 2016, pp. 5-21.

[10] T.Y. Khabrieva, "The legal system of the Russian Federation amid international integration," Herald of the Russian Academy of Sciences, vol. 85(2), 2015, pp. 93-99. contacts. They are being improved on the basis of interaction between States and peoples. It is emphasized that the international cooperation of the subjects of the regional legal 